\title{
REVISTA EVENTOS PEDAGÓGICOS: DE REVISTA-ESCOLAR AO QUALIS B1
}

\author{
Cristinne Leus Tommé ${ }^{1}$ \\ ORCID: 0000-0003-0323-7022 \\ Débora Pereira Lucas Costa 2 \\ ORCID: 0000-0002-0156-9544
}

\begin{abstract}
Resumo: Saber ler, interpretar, escrever e gerar conhecimento são tarefas intrínsecas ao cotidiano daqueles que se propõem a trabalhar nas salas de aula. Essa é a realidade dos acadêmicos de Pedagogia, na Universidade do Estado de Mato Grosso (UNEMAT), Câmpus de Sinop, que contam com uma iniciativa que lhes propicia publicar conhecimentos e experiências. A Revista Eventos Pedagógicos (REP’S) é o objeto desse relato de experiência. É um projeto de extensão que se iniciou em 2010, na disciplina Eventos Científicos da Metodologia de Pesquisa Educacional, como uma revista-escola, para divulgação das pesquisas acadêmicas realizadas durante o curso, em formato de artigos. Desde 2015, o periódico é avaliado pela Coordenação de Aperfeiçoamento de Pessoal de Nível Superior (Capes), com o Qualis B1, em Educação, pela qualidade, impacto e aderência. Atualmente, a REP’S conta com publicações de acadêmicos e, também, de pesquisadores de outras instituições de Ensino Superior do país e internacionais.
\end{abstract}

Palavras-chave: Pesquisa Acadêmica. Revista Científica. Educação. Socialização do conhecimento.

1 Doutora em Educação pela Universidade Federal do Rio Grande do Sul (2009), mestre em Educação pela Universidade Federal do Rio Grande do Sul (2000), graduada em História Licenciatura pela Universidade Federal do Rio Grande do Sul (1986) e em História Bacharelado pela Universidade Federal do Rio Grande do Sul (1987). É professora concursada na Universidade do Estado de Mato Grosso (Professor Adjunto nível 6). Professora permanente do Mestrado Acadêmico em Letras na UNEMAT. E-mail: cristinne.tome@unemat.br.

2 Mestranda em Letras pela Universidade do Estado de Mato Grosso (2019), graduada em Comunicação Social - Habilitação em Jornalismo pela Universidade Católica de Pelotas (2004). E-mail: deborajor@hotmail.com. 


\title{
REVISTA EVENTOS PEDAGÓGICOS: FROM SCHOOL-MAGAZINE TO QUALIS B 1
}

\begin{abstract}
Knowing how to read, to interpret, to write and to generate knowledge are tasks intrinsic to the daily life of those who propose to work in classrooms. This is the reality of the Pedagogy academics, at the Universidade do Estado de Mato Grosso (UNEMAT), Campus of Sinop, which count on an initiative that allows them to publish knowledge and experiences. The Revista Eventos Pedagógicos (REP's) is the object of this experience report. It is an extension project that began in 2010, in the discipline Eventos Científicos da Metodologia de Pesquisa Educacional, as a school-magazine, for the dissemination of academic research conducted during the course, in articles format. Since 2015, the magazine is evaluated by the Coordenação de Aperfeiçoamento de Pessoal de Nível Superior (Capes), with Qualis B1, in Education, for quality, impact and adherence. Currently, REP's has publications by academics and also by researchers from other higher education institutions in Brazil and other countries.
\end{abstract} Keywords: Academic research. Cientific magazine. Education. Socialization of knowledge.

\section{REVISTA EVENTOS PEDAGÓGICOS: DE REVISTA-ESCUELA AO QUALIS B1}

Resumen: Saber leer, interpretar, escribir y generar conocimiento son tareas intrínsecas al cotidiano de aquellos que se proponen a trabajar en las aulas. Esta es la realidad de los académicos de Pedagogía, en la Universidade do Estado de Mato Grosso (UNEMAT), Cámpus de Sinop, que cuentan con una iniciativa que les propicia publicar conocimientos y experiencias. La Revista Eventos Pedagógicos (REP's) es el objeto de ese relato de experiencia. Es un proyecto de extensión que se inició en 2010, en la disciplina Eventos Científicos da Metodologia de Pesquisa Educacional, como una revista-escuela, para divulgación de las investigaciones académicas realizadas durante el curso, en formato de artículos. Desde 2015, el periódico es evaluado por la Coordenação de Aperfeiçoamento de Pessoal de Nível Superior (Capes), con el Qualis B1, en Educación, por la calidad, impacto y adherencia. Actualmente, la REP's cuenta con publicaciones de académicos y, también, de investigadores de otras universidades de Brasil y de otros países.

Palabras clave: Investigación académica. Revista Científica. Educación. Socialización del conocimiento.

Submetido em: 10/12/2018

Aceito em: 20/12/2018

\section{INTRODUÇÃO}

Manter-se atualizado e continuamente revitalizado são desafios impostos a muitas profissões e, em especial, aos professores, agentes geradores de novos conhecimentos científicos e incentivadores de experimentos. Para que essas investidas 
possam ser socializadas, as revistas científicas apresentam-se como instrumentos indispensáveis. Através dos periódicos, conhecimentos passam a ser difundidos, discutidos, repensados, reformulados mediante a leitura por profissionais e estudantes de diferentes instituições. A relevância é ainda maior, quando as revistas científicas passam a ser eletrônicas atingindo leitores em diferentes países e que lidam direta ou indiretamente com as temáticas abordadas pelas publicações.

Haja vista a grande necessidade de divulgação, socialização e problematização de conhecimentos na área da Educação, interessa-nos, aqui, apresentar um relato de experiência sobre os resultados de um projeto de extensão, que se iniciou em uma das disciplinas do curso de Pedagogia, da Universidade do Estado de Mato Grosso (UNEMAT), Câmpus de Sinop. Trata-se da manutenção e evolução de um periódico eletrônico, a Revista Eventos Pedagógicos (REP'S), que tem por objetivo publicar e socializar semestralmente uma edição regular com artigos dos alunos do curso de Pedagogia, de pesquisadores da UNEMAT e Instituições de Ensino Superior.

O projeto é uma iniciativa da disciplina de Eventos Científicos da Metodologia de Pesquisa Educacional e já publicou dezenas de trabalhos em 25 edições, aceitando artigos e resumos científicos inéditos nas áreas de Educação, Ensino, Letras / Linguística e Sociologia, que contribuam para intensificar a socialização e correlação de conhecimentos na graduação, na pós-graduação e com a sociedade em geral. Trata-se de um projeto que, inicialmente, objetivava o ensino e incentivo de acadêmicos de Pedagogia à produção científica e que se ampliou conquistando o Qualis B1 em Ensino, pela Coordenação de Aperfeiçoamento de Pessoal de Nível Superior (Capes).

A revista tem oportunizado o contato das produções dos acadêmicos de graduação e pós-graduação com pesquisadores de outras instituições e com a comunidade, estreitando os espaços de questionamentos, trocas e crescimento.

\section{A DISCIPLINA DE EVENTOS CIENTÍFICOS DA METODOLO- GIA DE PESQUISA EDUCACIONAL}

\subsection{Matriz Curricular do Curso de Pedagogia 2007/2}

A Universidade do Estado de Mato Grosso (UNEMAT) foi criada, na cidade de Cáceres, em 1978, como um Instituto de Ensino Superior. Com o passar 
dos anos, atingiu status de Centro Universitário e Centro de Ensino Superior e buscou a expansão para outras cidades no interior do Estado, almejando sua transformação em Universidade. No ano de 1990, inaugura-se o Núcleo Regional de Sinop, com o oferecimento dos cursos de Licenciatura em Matemática, Letras e Pedagogia. Em 1993, a Unemat passa à condição de Universidade, tendo seu reconhecimento homologado no ano de 1999.

No segundo semestre de 2007, coloca-se em prática uma nova matriz curricular para o Curso de Pedagogia, da UNEMAT, Câmpus de Sinop, em busca da formação de um profissional professor, reflexivo, educador na gestão e docência de educação infantil, que atuasse também como pesquisador na área da educação e articulador dos processos educacionais da escola.

Um profissional com condições de diagnosticar e atuar na heterogeneidade do campo de trabalho caracterizada, por um lado, pela pulverização dos conhecimentos, por outro, pelos múltiplos locais para o exercício profissional: escolas, empresas, sindicatos, movimentos sociais, hospitais, etc. necessita ainda, ser capaz de coordenar a busca, participativa, de alternativas de ação. (UNEMAT, 2007, p. 33).

A nova matriz curricular implantada previa um trabalho interdisciplinar entre os professores, provocando uma ação coletiva, entrelaçando temas, incentivando o debate e reflexões epistemológicas. Os processos avaliativos eram conduzidos de maneiras mais amplas, não superficiais ou localizadas. Assim, como no caso da pesquisa científica realizada pelo aluno, os professores podiam avaliar uma mesma produção do acadêmico em diversos momentos de suas etapas no curso (UNEMAT, 2007, p. 36).

As orientações sobre Metodologia Científica se iniciavam no primeiro semestre da graduação, sendo ofertada uma nova disciplina, a cada ciclo, nesta ordem: Metodologia Científica I, Metodologia Científica II, Metodologia da Pesquisa Educacional I e, no quarto semestre, Metodologia Educacional II, quando havia a qualificação do Projeto de Pesquisa. No sétimo semestre, a disciplina de Metodologia da Pesquisa Educacional III, culminava com a defesa do Trabalho de Conclusão de Curso. As bancas dos Projetos de Pesquisa e dos Trabalhos de Conclusão de Curso eram compostas pelo professores da disciplina de pesquisa, o orientador e mais dois avaliadores (UNEMAT, 2007).

Também no sétimo semestre, nesse contexto de produção da pesquisa acadêmica, a disciplina de Eventos Científicos da Metodologia de Pesquisa Educacional, vinha como um momento integrador, em que o aluno fazia um 
recorte de seu Trabalho de Conclusão de Curso, e o apresentava, ao final da disciplina, em um evento para socialização de todas as produções. A disciplina era nova, não fora reformulada a partir de outra. A ementa previa a "Organização, realização e publicação dos resultados da pesquisa científica no evento Iniciação Científica na Educação", com 60 horas/aula.

O evento de socialização dos artigos dos alunos, ao final do semestre, recebia o nome de Jornada Pedagógica: as dimensões da investigação e práxis pedagógica no contexto escolar. A iniciativa era, assim, um dos espaços articuladores do currículo de Pedagogia, resultado de uma

[...] ação planejada e articulada pelo conjunto dos professores que desenvolvem seu trabalho pedagógico num respectivo semestre, sendo que cada um dos professores destinará dez por cento (10\%) da carga horária da sua disciplina para o planejamento e execução da jornada pedagógica. Esta por sua vez, deverá ser realizada em cada turma (semestre de formação), com no mínimo de duas noites de duração no final do semestre letivo. (UNEMAT, 2007, p. 18).

Em todos os semestres, os professores se engajavam para juntos promoverem as apresentações de estudos, ao final dos semestres. As Jornadas representavam o "encontro de experiências, reflexões, descobertas e desafios dos alunos e dos educadores de cada semestre, sendo um espaço que transpassa os muros das salas de aula." (UNEMAT, 2007, p. 18).

\subsection{Matriz Curricular do Curso de Pedagogia 2013}

A partir do segundo semestre de 2014, a disciplina de Eventos Científicos da Metodologia de Pesquisa Educacional (60 h/a) deixa de ser ofertada no sétimo semestre do curso de Pedagogia e passa a integrar a oitava fase do curso, fazendo parte do eixo articulador "Pesquisa Educacional". Busca-se um espaço para a "sistematização e teorização de estudos, investigações e reflexões, convergindo para duas produções: o Trabalho de Conclusão de Curso - TCC e um artigo publicado na Revista Eventos Pedagógicos - REP'S - que tem publicação semestral." (UNEMAT, 2013, p. 26).

Esse eixo de Pesquisa Educacional tem como finalidade

[...] estudos críticos e reflexivos acerca do espaço vivido como pessoa, como estudante e como profissional comprometido com a educação. As atitudes investigativas devem articular ações-reflexões-ações, na coexistência de uma ética-estética-política de valorização 
da vida, em suas múltiplas manifestações. Ela transversaliza momentos teóricos e atividades práticas (ensino, aprendizagens, estágios, atividades complementares). (UNEMAT, 2013, p. 25).

Fazem parte desse eixo as disciplinas: Metodologia Científica, Metodologia da Pesquisa em Educação I, Metodologia de Pesquisa em Educação II, Metodologia de Pesquisa em Educação III, Metodologia de Pesquisa em Educação IV, Eventos Científicos e Metodologia de Pesquisa Educacional, que passa a ser realizada na oitava fase formativa de Pedagogia.

Os semestres foram organizados por Fases Formativas, "repertórios de saberes inerentes a formação do pedagogo e são propostas para orientar o aluno na definição de um percurso formativo e de uma dinâmica para sua formação." (UNEMAT, 2013, p. 12). As disciplinas do curso são distribuídas em três núcleos, na formação das oito fases: Núcleo de Estudos Básicos, Núcleo de Aprofundamento e Diversificação de Estudos e Núcleo de Estudos Integradores, do qual faz parte a disciplina de Eventos Científicos da Metodologia de Pesquisa Educacional.

A mudança da disciplina de Eventos Científicos da Metodologia de Pesquisa Educacional, do sétimo semestre para a oitava fase, não acarretou em alterações na ementa, mas a socialização dos artigos na Jornada Pedagógica: articulações do Projeto Político-Pedagógico Escolar, passa a ocorrer integrada com as disciplinas de Didática III e IV. Assim, organizam-se três noites de evento, uma para cada disciplina, com o lançamento da Revista Eventos Pedagógicos (REP’S) e as apresentações dos artigos e dos projetos político-pedagógicos construídos em sala de aula, a partir de experiências nas escolas.

Esse espaço articulador da Jornada Pedagógica ocorre em todos os semestres letivos, com a participação de discentes e docentes, articulada pelo conjunto dos professores que atuam no curso (UNEMAT, 2013, p. 25).

\section{AREVISTA EVENTOS PEDAGÓGICOS:UMAREVISTA-ESCOLA}

Em meio as alterações na matriz curricular do curso de Pedagogia da UNEMAT/Sinop é que surge a Revista Eventos Pedagógicos (REP'S). Percebendo a qualidade dos trabalhos desenvolvidos na disciplina de Eventos Científicos da Metodologia de Pesquisa Educacional e apresentados na Jornada Pedagógica: articulações do Projeto Político-Pedagógico Escolar, a professora titular 
da disciplina Cristinne Leus Tomé percebeu ser possível ir além e ampliar a divulgação das produções. No início do segundo semestre de 2010, a docente, que se torna a editora-chefe do periódico, juntamente com o bibliotecário Luiz Kenji Umeno Alencar e o técnico-administrativo Erick Duclert Stoelben colocam no ar a primeira edição da Revista Eventos Pedagógicos (REP’S).

A meta era que a publicação fosse socializada até dezembro daquele ano. Para isso, são feitos contatos com outras instituições para a composição dos conselhos internacionais e nacionais e, no site da UNEMAT/Sinop, é acrescentada a nova revista da graduação do curso de Pedagogia, junto a outras já existentes.

A REP'S nasce com um diferencial no câmpus. Era "a revista dos alunos", adjetivo que perdura. Uma revista que está vinculada à existência de uma disciplina - Eventos Científicos da Metodologia de Pesquisa Educacional, do curso de Pedagogia. E isso é o que a distingue das demais publicações do câmpus. As demais são vinculadas diretamente aos cursos e não a uma disciplina. No caso específico do curso de Pedagogia, por exemplo, no segundo semestre de 2010 foram criados dois periódicos: "a dos alunos", a Revista Eventos Pedagógicos (REP’S) e "a revista dos professores", a Revista Educação Cultura e Sociedade (ECS).

Para o surgimento da REP'S, em sala de aula, durante o semestre, os alunos trabalharam em seus artigos e também participaram na composição do título da revista, do logotipo e das ideias iniciais de como ela deveria ser. O título nasce da composição do primeiro nome da disciplina "Eventos" e do curso de graduação de Pedagogia: Revista Eventos Pedagógicos. A sigla também é sugestão de uma aluna, aprovado pela turma: REP'S. O logotipo - um quadro branco riscado com giz em verde e com a sigla REP'S - lembrar o quadro de uma sala de aula, instrumento muito utilizado pelos profissionais de Pedagogia.

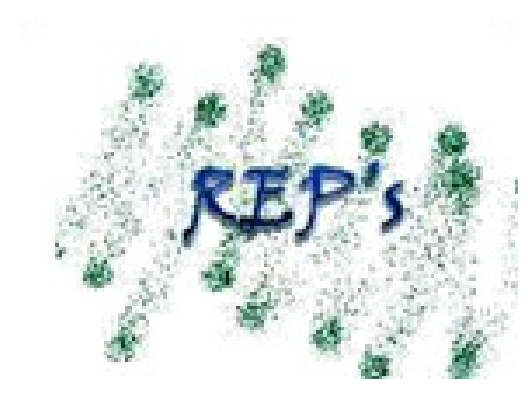

FIGURA 1: LOCOTIPO DO REP'S 
No primeiro semestre de 2011, bibliotecário Kenji solicita ao senhor Jaime Macedo França, supervisor de Artes e Publicações da UNEMAT - Sede Administrativa, o International Standard Serial Number (ISSN) - sigla em inglês para Número Internacional Normalizado para Publicações Seriadas. A identificação é concedida pelo Centro Brasileiro do ISSN, do Instituto Brasileiro de Informação em Ciência e Tecnologia. Em 9 de junho de 2011 chega a resposta de que o ISSN seria 2236-3165 para a publicação intitulada: "Eventos Pedagógicos" e tendo como abreviatura "Even. Pedagóg."

Entre 2010/2 e 2014/1, os alunos realizam a produção dos artigos para a Revista, juntamente com a disciplina de Metodologia da Pesquisa Educacional III, na qual desenvolvem o texto do Trabalho de Conclusão de Curso (TCC). Ao final do semestre, em dezembro, os artigos prontos foram publicados na página da UNEMAT/Sinop e houve a primeira apresentação dos artigos, na modalidade comunicação oral e lançamento da REP'S, cujo tema do volume 1, número 1, escolhido pela turma foi "Educação e Diversidade".

Um marco na história da REP'S foi a migração do periódico do site da UNEMAT-Sinop para a plataforma Open Journal Systems (OJS), no primeiro semestre de 2011, através do endereço http://sinop.unemat.br/projetos/revista/index. php/eventos. Essa visibilidade proporcionou maior acesso ao público externo à UNEMAT. A mudança também propicia que os próprios alunos realizem seus cadastros e submissões de artigos na plataforma. Desde então, ao acessar a página principal da REP'S, o visitante pode verificar as chamadas públicas mais recentes para a publicação de trabalhos e consultar informações sobre o histórico da revista, os conselhos, os indexadores, além de realizar seu cadastro para futuras submissões. Ao ingressar na seção de edições anteriores, encontra-se todos os textos publicados em formato PDF para leitura e download.

\section{SEÇÕES ABERTAS INDEPENDEN- TES: $\quad$ CONVIDANDO $\quad O$ PÚBLICO} A PUBLICAR

No primeiro semestre de 2011, quando a Revista ainda estava armazenada na plataforma da UNEMAT/Sinop, foram abertas seções de postagens aos estudantes e professores. Muitos alunos ainda não conheciam o sistema de postagens 
de trabalhos acadêmicos, nem o processo que envolvia: como fazer o cadastro, a submissão, a avaliação e a decisão final.

A primeira seção aberta, de fluxo contínuo, foi no sentido de ensinar aos alunos esse processo e se chamou Balaio de Penélope. A professora Cristinne, em conversa com os alunos do curso de Letras, comentou sobre a opção de submissão de trabalhos - não necessariamente acadêmicos e aberto a todos os gêneros literários, produções em diferentes gêneros escritos ou não (graphês). Abre-se o contato do graduando com uma revista eletrônica. O nome da sessão "Balaio de Penélope" surge da sugestão de um acadêmico: o balaio da Penélope é um mundo de opções, de cores, de linhas, um momento em que o aluno não se sentisse pressionado em publicar, mas que o fizesse por decisão própria. E ficou: Portal Balaio de Penélope.

O texto de Apresentação de chamada na página da Revista era:

Seja bem-vindo ao Balaio de Penélope! Tu te lembras da moça que ficou tecendo enquanto aguardava o retorno de seu amado Ulisses? Pois é, Penélope. Ela tecia e destecia na esperança de que seu amado retornasse da Guerra de Tróia. Imaginem a cena: ela sentada em uma cadeira de balanço, a luz entrando pela janela, a roda de fiar, o tear, um cesto cheio de fios coloridos, linhas, agulhas, tesouras, alfinetes, rendas, dedais, fita métrica, botões, corantes ao seu lado. Um cesto cheio de possibilidades, desejos de um vir-a-ser. Escolha a tua agulha, desenrole o teu novelo, puxe o fio da meada, organize a tua trama e teça a tua renda! O recebimento dos trabalhos será constante, em arquivo PDF. Cadastre-se e envie para nós! (ARQUIVO da REP’s, 2019).

A partir de 2014, o portal Balaio de Penélope passou a ser destinado somente aos alunos matriculados em cursos de graduação e, aos poucos, a seção deixou de ter seu objetivo inicial de introdução à publicação. Novas mídias eletrônicas, através das quais os autores passam a ser os próprios administradores, sem a necessidade de um intermediário. Assim, em 14 de março de 2018 foi enviado um e-mail aos autores que tinham trabalhos no Portal Balaio de Penélope para que recolhessem seus trabalhos. A seção foi encerrada em 01 de junho de 2018.

Outra seção de destaque no percurso da REP'S é a Na Estante dos TCCs, como um espaço aberto e independente. O propósito era ser um local para que todos pudessem publicar suas pesquisas. Na chamada da página, o texto de apresentação era:

Este é o momento de você tirar o pó de sua Monografia e mostrá-la ao mundo! Na Estante dos TCCs é a sua estante virtual destinada a abrigar os Projetos de Pesquisa, Relatórios 
Finais, Trabalho de Conclusão de Curso (TCC), Trabalho de Graduação Interdisciplinar (TGI), Monografias de Especialização / Aperfeiçoamento, Dissertações e Teses, isto é, trabalhos de finalização de Curso ou Programa e que tenham sido realizados sob a orientação de um professor. (ARQUIVO da REP’S, 2019).

Vários alunos e professores enviaram seus trabalhos de graduação para a seção, com o intuito de divulgar e apresentar aos colegas suas produções. A iniciativa perdurou até julho de 2014, quando os TCCS passam a ser disponibilizados online pela biblioteca da UNEMAT. Assim, os quarenta e quatro trabalhos que compunham $\mathrm{Na}$ Estante dos TCCs foram enviados ao bibliotecário Luiz Kenji Umeno Alencar para fazerem parte da biblioteca central da UNEMAT. E a seção foi encerrada em setembro de 2014.

A Seção Livros criada no primeiro semestre de 2011 também merece destaque. Em 30 de maio de 2011, a editora-chefe da REP'S, Cristinne, conversa com o bibliotecário Kenji sobre a possibilidade de abertura de uma seção para que professores e autores pudessem publicar seus livros já esgotados ou produzidos em sala de aula. No Câmpus de Sinop, alunos das licenciaturas em Pedagogia e Letras e dos bacharelados produziam livros de poesias, compêndios de artigos nas disciplinas e que, organizados formaram parte desta seção. O texto de apresentação na página da Revista era:

\footnotetext{
Você que tem seu livro guardado embaixo da pilha de camisetas no guarda-roupa; ou perdido entre arquivos no seu computador; ou ainda já tenha publicado há tempos de antigamente mas gostaria de republicá-lo: que tal pensar na ideia?
}

Você que é professor e fez uma atividade em sala de aula muito interessante: pedagógica, construtiva, interativa, cidadã... uma atividade digna de ser mostrada aos outros. Que tal mostrar?

Você que não é escritor, nem professor, mas é construtor ou engenheiro, herbanário ou médico, dona de casa ou dona de casas, terapeuda ou advogada, jardineiro ou paisagista, motorista de trator, bombeiro, padeiro, moço do correio, gerente de banco, dono do mercado (outro: ) o que você acha de publicar aquela sua pilha de poesias, de canções, de contos? Vamos? (ARQUIVO da REP’S, 2019).

Quando um livro era publicado na Seção Livros, fazia-se uma matéria de divulgação no site de notícias da UNEMAT, como ocorreu em 9 de maio de 2012, com a chamada "Revista Eventos Pedagógicos publica versão digital do livro 
'Primeiro', obra que lançou a poesia de Santiago Villela Marques e se encontra hoje fora de catálogo".

A publicação da versão digital do livro do autor pela Eventos Pedagógicos faz parte de uma iniciativa da revista para disponibilizar obras de difícil acesso em versão impressa. Com isso, a revista busca ampliar a divulgação do saber e da produção literária, especialmente de autores regionais. (UNEMAT, Notícias, 9 maio 2012).

Essa seção, assim como as outras, perderam seu objetivo principal, uma vez que a própria biblioteca central da UNEMAT de Sinop passou a disponibilizar essa opção de consulta. Os livros que compunham essa seção foram enviados ao bibliotecário Kenji para que dispusesse as obras no site da UNEMAT, em 2014.

\section{O PROJETO DE EXTENSÃO “REVISTA EVENTOS PEDAGÓGICOS”}

Durante os primeiros anos de publicação da Revista Eventos Pedagógicos houve um fortalecimento das edições, com participação de outras instituições o que levou a editora-chefe a buscar o reconhecimento como um Projeto de Extensão. Assim, a primeira portaria de funcionamento foi publicada em 2012, e seguiu-se na ordem:

\section{Portarias:}

No 1984/2012 - Projeto de Extensão. Coordenadora: Cristinne Leus Tomé. Vigência: 01/10/2012 a 01/10/2013.

No 2107/2013 - Projeto de Extensão. Coordenadora: Cristinne Leus Tomé. Vigência: 02/10/2013 a 01/10/2014.

No 546/2016 - Projeto de Extensão. Coordenadora: Cristinne Leus Tomé. Vigência: 26/02/2016 a 31/12/2017.

No 1031/2018 - Projeto de Extensão. Coordenadora: Cristinne Leus Tomé. Vigência: 01/01/2018 a 31/12/2019.

E dois bolsistas: de 2015-2016 Jhonatan Matos de Souza e de 20162017 Nathali Souza Ribeiro. 
A primeira avaliação da Revista Eventos Pedagógicos (REP’S) pela Coordenação de Aperfeiçoamento de Pessoal de Nível Superior (Capes), do Ministério da Educação e Cultura (MEC), aconteceu três anos após a publicação de sua primeira edição. Em 2013, o periódico atingiu os conceitos Ensino B3, Educação B5, Interdisciplinar B5, Letras/Linguística C e Sociologia C.

A iniciativa solidificou-se com o passar dos semestres e das publicações e o trabalho foi intensificado a fim de melhorar a avaliação Qualis. Para isso, iniciou-se o processo de inserção da REP'S em indexadores, bases de dados e diretórios nacionais e internacionais. Atualmente, revista encontra-se disponível nas plataformas Diretório de Políticas de Acesso Aberto de Revistas Científicas Brasileiras (Diadorim), Sumários de Revistas Brasileiras (Sumários.org), Sistema Regional de Información en Línea para Revistas Científicas de América Latina, el Caribe, España y Portugal (Latindex), La Criée: périodiques en ligne, Red Iberoamericana de Innovación y Conocimiento Científico (REDIB), Portal de Periódicos CAPES/MEC e Index Copernicus International (ICI).

Paralelamente, iniciaram-se convites para professores de outras instituições nacionais e internacionais comporem o Conselho Consultivo do periódico. A revista passou a ser membro do Committee on Publication Ethics (COPE) e do Comitê de Ética em Pesquisa - UNEMAT, além de possuir a licença de direitos autorais Creative Commons BY 3.0.

Atualmente, a REP'S está enquadrada com Qualis B1 Ensino, B3 Planejamento Urbano e Regional / Demografia, B4 Ciências Ambientais, Educação Física, Interdisciplinar, Linguística e Literatura e Sociologia. Para acompanhar a representatividade e o alcance das publicações realizadas pela REP'S, a equipe da Revista dispõe de um site de estatística, o histats.com. Os dados indicam que o interesse por vários autores em publicar suas produções na Revista Eventos Pedagógicos, vem aumentando, dando credibilidade ao projeto. A revista conta ainda com um perfil nas redes sociais. Através do Facebook, promove-se a aproximação entre pesquisadores, leitores e as produções científicas.

5.1 Comissões, Conselhos e Seções

A REP'S conta com um privilegiado grupo que compõe os conselhos Editorial, Consultivo Nacional e Internacional e de Tradutores, além dos 
pareceristas. Esses profissionais são, em sua maioria, doutores, e as informações sobre os conselhos e comissões estão disponíveis no site da revista.

O Conselho Editorial é um fórum deliberativo composto pelo editor-chefe e pelos editores das áreas de Educação e Letras vinculados a Instituições de Ensino Superior que participam das publicações da revista. O mandato de cada membro é de um ano, permitindo a sua permanência sempre que o Conselho considerar pertinente. $\mathrm{O}$ mandato do editor-chefe é semestral, visto que esta é uma atribuição do professor concursado em Metodologia Científica (UNEMAT), responsável pela disciplina de Eventos Científicos da Metodologia de Pesquisa Educacional, do Curso de Pedagogia. Até a data de publicação deste trabalho, a posição é atribuída à professora doutora Cristinne Leus Tommé, que é também a idealizadora da REP'S. Além da editora-chefe, integram esse conselho os professores doutores Lúcio José Dutra Lord e Ivone Cella da Silva.

Entre outras atividades, cabe a esse grupo a organização e publicação de um Número Regular com as produções da disciplina de Eventos Científicos da Metodologia de Pesquisa Educacional (Julho/Dezembro) e uma Edição Especial Temática semestral com propostas temáticas enviadas pela comunidade científica (Maio/Outubro). O Número Regular é dividido em seis seções: Apresentação (escrita por um professor convidado conhecedor da temática), Introdução (escrita pelos organizadores e/ou autores convidados), Artigos (alunos do sétimo semestre de Pedagogia), Entrevista (temática ao número publicado), Resumos e Livre (pesquisas acadêmicas na graduação e pós-graduação).

Já a Edição Especial Temática, que visa a publicação dos resultados de pesquisas realizadas pela comunidade científica em nível de pós-graduação (Mestrados e Doutorados), contém quatro seções: Apresentação (escrita por um doutor convidado), Introdução (elaborada pelos organizadores), Artigos (enviados pela comunidade acadêmica) e Entrevista (temática ao número publicado). Os trabalhos submetidos a essas edições da REP’S passam pelo crivo de um corpo de pareceristas, formado por professores convidados de notório saber.

A REP'S conta ainda com os Conselhos Consultivos Nacional e Internacional compostos por pesquisadores brasileiros e de instituições de outros países - como Universidade de Paris 8 (França), Universidade Catolica de Cuyo (Argentina), Universidade ORT (Uruguai), Universidade Nacional de Río Cuarto (Argentina), Universidad de Santiago de Chile (Chile), 
Universidad de la República (Uruguai), Universidad de La Serena (Chile), Universidade Ramon Llull (Espanha) e Universidade de Macau (China). Outro grupo que completa a organização do periódico é o Conselho de Tradutores, formado por um coordenador e por um corpo de tradutores de línguas Inglesa e Espanhola.

\subsection{Trajetória de publicações}

A revista conta atualmente com 25 edições publicadas. A primeira foi a V.1, n. 1 (2010), onde o "V" indica o volume da edição e o "n. 1" indica o $1^{\circ}$ semestre do ano de referência. Essa edição abrangeu o período de agosto a dezembro de 2010, tendo como tema Educação e Diversidade. Outros dois números regulares foram publicados no ano de 2011, apresentando as temáticas Relatos de Experiências e Produções Inovadoras na Universidade. Em 2012, publicou-se três edições: Introdução à Análise do Discurso, Políticas Públicas e Multiculturalismo e Ensaios investigativos em Educação Matemática. $\mathrm{O}$ ano seguinte foi o de trabalho das temáticas As perspectivas do processo educacional na formação humana e Vivências no espaço escolar, publicadas em dois volumes.

Em 2014, os volumes abordaram os temas O professor de inglês da escola pública como criador-de-sentidos, Gestos de Leitura, Estudos sobre a Universidade e Matrizes e práticas curriculares sob o olhar das políticas públicas.

Acadêmicos e pesquisadores, em 2015, tiveram a oportunidade de divulgar suas produções sobre Articulação universidade e escola nas ações do ensino de matemática e ciências, Educação de 0 a 3 anos em espaços de vida coletiva, Desigualdade e diversidade étnico-racial na educação infantil e Observatório da Educação: descrevendo as produções de conhecimento na relação universidade-escola.

Em 2016, os volumes da REP'S apresentaram as temáticas Universidades: desafios e perspectivas na contemporaneidade, Formação de professores e desafios da escola no século XXI e Experiências em Educação do Campo: perspectivas e práticas pedagógicas. Para 2017, os assuntos norteadores das duas edições publicadas foram Caminhos no/para o ensino e a aprendizagem de Língua Inglesa em espaços escolares e Formação de Professores no ensino de Ciências e Matemática. Já os três volumes mais recentes, publicados em 2018, 
abordaram Sociologia da Educação, História, Filosofia e EducaçÃo Matemática e Documentação Pedagógica: experiências com projetos.

\section{CONSIDERAÇÕES FINAIS}

A Revista Eventos Pedagógicos, uma iniciativa que surge em uma disciplina do curso de Pedagogia da UNEMAT/Sinop, expandiu-se e tornou-se um projeto de extensão. O periódico tem ampliado sua representatividade junto à comunidade científica e à sociedade em geral o que culmina com sua avaliação com o Qualis B1 Ensino, pela Capes.

Ao longo dos seus nove anos de existência tem sido importante ferramenta para promoção da pesquisa e da ciência. Através da iniciativa, acadêmicos aprendem nas aulas o que é uma Universidade e o tripé que a compõe: ensino, pesquisa e extensão. Os acadêmicos passam a entender que a Revista Eventos Pedagógicos faz parte do eixo extensão. Além disso, os estudantes exercitam a organização de um evento, a Jornada Pedagógica, e do lançamento da Revista.

Aos universitários é dada a oportunidade de exercitarem a elaboração de um artigo científico seguindo um template específico voltado a um periódico, passando pelas etapas de organização de um resumo (ABNT, 6028, 2003), relembrar e tirar dúvidas sobre citações (ABNT, 10520, 2002) e referências (ABNT, 6023, 2018). Há ainda a experimentação do contato com os tradutores que realizarão o abstract dos trabalhos.

A turma é dividida em grupos de leitura, formatação e verificação de plágio oportunizando que um mesmo artigo seja lido por mais de uma pessoa, seja verificada a formatação antes da entrega final para avaliação da disciplina.

Na plataforma da revista, os estudantes aprendem a submeter os trabalhos acadêmicos, organizam a capa da edição, atuam desde a elaboração até o lançamento, durante a Jornada Científico-Pedagógica, também organizada pelos estudantes. Ao acadêmicos, cabe, ainda, a tarefa de convidar a comunidade para que submeta produções à Seção Resumos (que serão avaliados pelo Conselho Editorial), além de cadastrar os demais alunos na Plataforma da Revista.

A REP'S é, assim, uma revista-escola que cresceu e expandiu seus horizontes. Um projeto de extensão que tem apresentado relevância social e acadêmica e que tem crescido ao longo dos anos, uma vez que, no espaço acadêmico, o aluno-pesquisador acompanha todas as fases de organização de um periódico, sendo incentivado a manter essa prática científica ao longo de sua vida 
profissional, após o término da graduação. A publicação regular, que se iniciou para atender às exigências da disciplina, ganhou expressão e hoje posiciona-se como importante ferramenta para divulgação da pesquisa no país. A revista eletrônica é, então, um diferencial, uma atividade que vai além dos parâmetros estabelecidos para uma disciplina.

\section{REFERÊNCIAS}

UNIVERSIDADE DO ESTADO DE MATO GROSSO. Departamento de Pedagogia. Reestruturação Curricular do Curso de Pedagogia. Sinop: UNEMAT, 2007. Disponível em: http://sinop.unemat.br/site/download/ projetos_pedag\%C3\%B3gicos/projeto_pedagogico_pedagogia.pdf. Acesso em: 06 maio 2018.

UNIVERSIDADE DO ESTADO DE MATO GROSSO. Notícias. Revista "Eventos Pedagógicos" publica versão digital do livro "Primeiro", obra que lançou a poesia de Santiago Villela Marques e se encontra hoje fora de catálogo. Sinop: UNEMAT, 9 maio 2012. Disponível em: http://sinop. unemat.br/site_antigo/noticia_ver.php?id=1034. Acesso em: 7 maio 2018. UNIVERSIDADE DO ESTADO DE MATO GROSSO. Faculdade de Educação e Linguagem. Licenciatura em Pedagogia. Projeto Curricular Pedagógico do Curso de Licenciatura em Pedagogia. Sinop: UNEMAT, 2013. Disponível em: http://portal.unemat.br/media/files/1_1_1\%20-\%20 PPC\%20de\%20Pedagogia\%20-\%20Sinop.pdf. Acesso em: 06 maio 2018. 